\title{
Pengawetan Perendaman Dingin dan Panas Dingin Kayu Trembesi (Albizia Saman) menggunakan Pengawet Boraks
}

\author{
Safat Amin \\ Laboratorium Biologi dan \\ Pengawetan Kayu Fakultas \\ Kehutanan, Universitas \\ Mulawarman \\ Samarinda, Indonesia \\ safat@gmail.com
}

\author{
Agung Priyo Hutomo \\ Laboratorium Biologi dan \\ Pengawetan Kayu Fakultas \\ Kehutanan, Universitas \\ Mulawarman \\ Samarinda, Indonesia \\ agung_priyo@yahoo.co.id
}

\author{
Zainul Arifin \\ Laboratorium Biologi dan \\ Pengawetan Kayu Fakultas \\ Kehutanan, Universitas \\ Mulawarman \\ Samarinda, Indonesia \\ zainul_forestry@yahoo.com
}

\begin{abstract}
Penelitian ini bertujuan untuk mengetahui nilai retensi dan keefektifan bahan pengawet Boraks (Na2B4O7.10H2O) terhadap serangan rayap tanah (Subteranean termites) pada kayu Trembesi (Albizia saman) dengan metode pengawetan dan konsentrasi bahan pengawet yang berbeda. Penelitian ini dilakukan di Laboratorium Biologi dan Pengawetan Kayu, Fakultas Kehutanan, Universitas Mulawarman Samarinda. Seluruh data diolah menggunakan pola percobaan $3 \times 2$ dalam rancangan faktorial acak lengkap dengan 10 kali

mendapatkan perlakuan pengawetan, sedangkan contoh uji kontrol sebesar 9,573\%. Nilai tersebut apabila dibandingkan dengan SNI 01-7207-2006 tentang uji ketahanan kayu dan produk kayu terhadap organisme perusak kayu termasuk dalam kelas I (sangat tahan) sampai dengan kelas II (tahan), sedangkan untuk kontrol termasuk dalam kelas III (sedang). Sehingga dapat dikatakan bahwa kehilangan berat contoh uji yang telah diberi perlakuan cukup efektif untuk pencegahan dari serangan rayap tanah.
\end{abstract} ulangan. Parameter yang diukur adalah kadar air, Kerapatan kering udara, kerapatan kering tanur, uji retensi, dan persentase uji kehilangan berat dengan menggunakan metode perendaman dingin, perendaman panas dingin dan konsentrasi $1 \%, 2 \%$, dan $4 \%$. Hasil penelitian menunjukkan bahwa nilai rataan kadar air kering udara Trembesi adalah 11,528\% dengan koefisien variasi sebesar $4,445 \%$. Nilai rata-rata kerapatan kering udara dan kerapatan kering tanur masing-masing adalah $0,460 \mathrm{~g} / \mathrm{cm} 3$ dan $0,427 \mathrm{~g} / \mathrm{cm} 3$ dengan koefisien variasi masing-masing sebesar $8,500 \%$ dan $8,364 \%$. Konsentrasi bahan pengawet Boraks dan metode pengawetan berpengaruh sangat signifikan terhadap retensi bahan pengawet, semakin tinggi konsentrasi pengawet maka semakin tinggi pula nilai retensi nya. Metode perendaman panas dingin akan menghasilkan nilai retensi lebih tinggi dibanding metode perendaman dingin. Interaksi antara faktor konsentrasi dan metode pengawetan berpengaruh sangat signifikan terhadap retensi, dimana rataan nilai retensi tertinggi dan paling memberikan pengaruh terhadap perlakuan interaksi yang lain terdapat pada konsentrasi $4 \%$ dengan metode pengawetan panas dingin sebesar 2,662 kg/m3. Konsentrasi dan interaksi menunjukan adanya pengaruh yang tidak signifikan terhadap nilai kehilangan berat, sedangkan metode pengawetan menunjukan pengaruh yang sangat signifikan dengan nilai kehilangan berat terendah yang paling berpengaruh adalah perendaman panas dingin sebesar $1,484 \%$. Namun perlakuan pengawetan secara umum telah mampu menurunkan kehilangan berat kayu. Persentase kehilangan berat contoh uji yang dihasilkan dalam penelitian diperoleh nilai dengan kisaran 1,339-3,678\% untuk contoh uji yang
Keywords - Pengawetan rendaman dingin dan panasdingin, kayu trembesi, pengawet boraks

\section{PENDAHULUAN}

Pengawetan kayu bertujuan memanfaatkan pemakaian jenis-jenis kayu yang berkelas keawetan rendah dan sebelumnya belum pernah digunakan dalam pemakaian. Mengingat sumber kayu di Indonesia memiliki potensi hutan yang cukup luas dan banyak aneka ragam dari jenis kayunya Dumanauw dan Virsarany (1981).

Menurut Hunt dan Garratt (1986) bahwa metode pengawetan tanpa tekanan lebih murah, mudah diterapkan, peralatan yang digunakan sederhana sehingga mudah dioperasikan seperti metode perendaman, pemulasan, dan pencelupan. Salah satu kegunaan kayu yang tidak kalah pentingnya yaitu sebagai bahan bangunan berupa rumah yang merupakan kebutuhan primer sehingga merupakan kebutuhan pokok yang harus dipenuhi. Membangun rumah, bangunan pasti membutuhkan kayu.

Menurut Duljapar (1996) saat ini di Indonesia tercatat ada \pm 4.000 jenis kayu yang tersebar di seluruh nusantara, $15-20 \%$ dari jumlah tersebut termasuk jenis kayu dengan keawetan tinggi (kelas I dan II) dan 80-85\% sisanya adalah jenis kayu yang kurang menguntungkan (kelas awet III, IV dan V). Tidak semua jenis kayu tersebut mempunyai tingkat keawetan yang sama, karena tingkat keawetan kayu sangat beragam menurut jenis dan umur kayu.

Berdasarkan hal tersebut, bahwa jenis kayu awet sedikit jumlahnya sementara penggunanya sangatlah banyak, sedangkan kayu yang tidak awet sangat banyak 
tetapi penggunanya masih terbatas, sehingga perlu dipikirkan bagaimana cara meningkatkan nilai keawetan kayu agar pemanfaatan kayu tidak hanya terfokus pada jenis-jenis kayu yang awet saja. Oleh karena itu pengawetan kayu penting artinya karena dikhawatirkan produksi jenis kayu yang awet dalam masa mendatang tidak akan terpenuhi lagi (Dumanauw, 2001).

Kayu Trembesi (Albizia saman) yang berasal dari genus Albizia memiliki persebaran luas di wilayah beriklim tropis seperti Indonesia. Pertumbuhannya pun cepat sehingga jumlahnya termasuk besar. Trembesi memiliki tingkat kepadatan menengah yang masih kalah dibanding jati. Tingkat keawetan IV, tingkat kuat III, dan berat jenis 0,6. Kayu ini bisa besar dalam waktu relatif lebih cepat dibanding kayu jenis lainnya seperti mahoni. Dari sifat ini, kita bisa memperoleh kayu dengan diameter yang lebar hingga 1,5 meter. Adapun beberapa kekurangan kayu Trembesi. Dua dari berbagai kekurangan tersebut adalah tingkat keawetan dan kekuatannya. Trembesi masuk dalam kelas awet IV. Ini artinya, kayu tersebut sangat rentan diserang hama seperti jamur, rayap, dan kutu bubuk. Sedangkan dari aspek kekuatan, kayu ini termasuk dalam kelas kuat III.

Saat ini dikenal beberapa metoda pengawetan seperti rendaman dingin, rendaman panas dingin, metoda vakum tekan dengan sel kosong dan metoda vakum tekan dengan sel penuh. Metoda Rendaman dingin merupakan salah satu proses sederhana untuk mengawetkan kayu perumahan dan gedung yang tercantum dalam standar Kehutanan Indonesia, nomor SKI.C-m-001, tahun 1987. Proses ini sesuai untuk mengawetkan kayu kering dan setengah kering yang umum digunakan dalam pembuatan bangunan dewasa ini. Selain itu peralatan yang diperlukan untuk proses ini sederhana dan dapat disesuaikan dengan keadaan. Untuk rendaman panas dingin dianjurkan mengunakan bahan pengawet golongan BFCA (Martawijaya et al, 1984).

Percobaan perendaman panas dingin sudah dimulai oleh Supriana (1975) terhadap enam jenis Dipterocarpaceae dengan menggunakan larutan asamborat tiga persen. Hasilnya menunjukan bahwa dengan rendaman panas dua jam dan rendaman dingin selama satu hari sudah dapat mencapai retensi dan penetrasi yang disyaratkan.

Berdasarkan uraian di atas tersebut maka dilakukan penelitian pengawetan pada kayu Trembesi (Albizia saman) dengan menggunakan bahan pengawet boraks dan ketahanannya terhadap serangan rayap tanah.

Penelitian ini bertujuan untuk mengetahui nilai retensi dan keefektifan bahan pengawet Boraks terhadap serangan rayap tanah (Subteranean termiittes) dengan menggunakan jenis kayu Trembesi (Albizia saman) dengan metode dan konsentrasi yang berbeda. Hasil penelitan ini diharapkan dapat memberikan informasi kepada seluruh masyarakat dan perusahaan kayu tentang penggunaan proses pengawetan tanpa tekanan dan penggunaan bahan pengawet secara optimal agar diperoleh hasil pengawetan yang efektif dan efisien.

\section{METODELOGI}

\section{A. Tempat dan Waktu Penelitian}

Penelitian ini akan dilakukan di Laboratorium Biologi dan Pengawetan Kayu sedangkan proses uji rayap dilakukan di area Workshop, Fakultas Kehutanan, Universitas Mulawarman Samarinda. Penelitian ini dilaksanakan selama kurang lebih 5 bulan.

\section{B. Alat dan Bahan Penelitian}

Peralatan yang digunakan dalam penelitian ini antara lain: keranjang sampel kayu, caliper digital, timbangan digital, kamera, arloji, oven pengeringan, desikator, gelas ukur, bak pengawetan, pemberat, kain, air, dan alat tulismenulis.

Bahan baku yang digunakan dalam penelitian ini adalah jenis kayu Trembesi (Albizia saman) dengan diameter $\pm 40 \mathrm{~cm}$ yang berasal dari wilayah kampus UNMUL Samarinda. Adapun bahan-bahan yang digunakan cat minyak dipergunakan untuk menutupi permukaan bidang transversal dari sampel uji kayu.

C. Prosedur Penelitian

1. Pembuatan contoh uji

Dalam penelitian menggunakan Trembesi (Albizia saman) sebagai bahan yang akan diawetkan dengan bahan pengawet boraks yang telah dipersiapkan.

Pelaksanaan pembuatan sampel uji diuraikan sebagai berikut:

- Pohon Trembesi ditebang dengan diameter $\pm 40 \mathrm{~cm}$. Kemudian dipotong menjadi 3 bagian dengan ukuran panjang $40 \mathrm{~cm}$.

- Potongan tersebut kemudian dibuat stik dengan ukuran $2 \mathrm{~cm} \times 2 \mathrm{~cm} \times 40 \mathrm{~cm}$. stik tersebut di potong dan di ambil pada bagian tengahnya dengan ukuran 2 $\mathrm{cm} \times 2 \mathrm{~cm} \times 10 \mathrm{~cm}$ dan dibuat contoh uji untuk menghitung kadar air dan kering tanur masingmasing 10 buah dengan ukuran $2 \mathrm{~cm} \times 2 \mathrm{~cm} \times 2 \mathrm{~cm}$. sedangkan stik yang berukuran $2 \mathrm{~cm} \times 2 \mathrm{~cm} \times 15 \mathrm{~cm}$ digunakan sebagai contoh uji retensi.

- Setelah dikeringkan selama 7 hari, dimasukan semua contoh uji kedalam ruang konstan hingga diperoleh kadar air keseimbangan $( \pm 12 \%)$. Selanjutnya dilakukan pengukuran kadar air kayu dan kerapatan kayu sebelum diawetkan.

2. Pengukuran kadar air normal dan kerapatan

Pengukuran kadar air kering udara dan kerapatan adalah sebagai berikut:

Contoh uji diambil ukuran $2 \mathrm{~cm} \times 2 \mathrm{~cm} \times 2 \mathrm{~cm}$.

Lalu diukur dimensi untuk mengetahui volume kering udara dan juga ditimbang beratnya untuk mengetahui massa kering udara, setelah itu dihitung kerapatan kering udaranya dengan rumus sebagai berikut:

$$
\rho_{\mathrm{u}}=\frac{\mathrm{Mu}}{\mathrm{Vu}}
$$

Dimana:

$$
\begin{aligned}
& \rho_{u}=\text { Kerapatan kering udara }\left(\mathrm{g} / \mathrm{cm}^{2}\right) \\
& \mathrm{M}_{\mathrm{u}}=\text { Massa Kering Udara }(\mathrm{g}) \\
& \mathrm{V}_{\mathrm{u}}=\text { Volume Kering Udara }\left(\mathrm{cm}^{3}\right)
\end{aligned}
$$


- Selanjutnya dimasukan ke dalam oven $\left(100^{\circ} \mathrm{C}\right)$ selama 48 jam.

- Contoh uji dikeluarkan dari oven, kemudian dimasukan kedalam desikator selama 15 menit.

- Contoh uji dikeluarkan dari desikator.

- Kemudian, ditimbang beratnya untuk mengetahui nilai massa kering tanur dan diukur dimensinya untuk mengetahui olume kering tanurnya.

- Selanjutnya, dihitung nilai kadar air kering udara dengan menggunakan rumus berikut:

$$
\mathrm{Ka}=\frac{\mathrm{Mu}-\mathrm{Mo}}{\mathrm{Mo}} \times 100 \%
$$

Dimana:

$\mathrm{Ka}=\quad$ Kadar Air Kering Udara $(\%)$

$\mathrm{Mu}=\quad$ Massa Kering Udara $(\mathrm{g})$

Mo $=\quad$ Massa Kering Tanur $(\mathrm{g})$

- Kemudian, dihitung kerapatan kering tanurnya menggunakan rumus berikut:

$$
\begin{aligned}
& \rho_{\mathrm{KT}}=\frac{\mathrm{M} \mathrm{KT}}{\mathrm{VKT}} \\
& \text { Dimana: } \\
& \text { - } \rho_{\mathrm{KT}}=\text { Kerapatan Kering Tanur } \\
& \left(\mathrm{g} / \mathrm{cm}^{2}\right) \quad \text { Massa Kering Tanur }(\mathrm{g})
\end{aligned}
$$

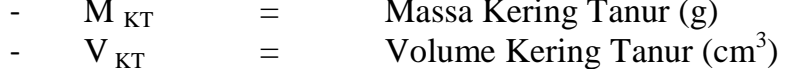

Dalam penelitian ini disiapkan konsentrasi bahan pengawet boraks dengan 3 tingkatan konsentrasi yang berbeda yaitu $1 \% ; 2 \% ; 4 \%$, untuk memperoleh konsentrasi tersebut akan dibuat larutan pengawet dengan mencampurkan bahan pengawet dengan pelarut air.

4. Proses pengawetan

a. Perendaman dingin

Proses pengawetan menggunakan metode perendaman dingin dengan tahapan sebagai berikut :

1. Sebelum diawetkan sampel dikeringudarakan lebih dulu, lalu dicat permukaan transversalnya.

2. Setelah tercapai kadar air kering udara, kemudian ditimbang dan diukur dimensinya.

3. Contoh uji dimasukan dan disusun ke dalam bak, diberi stik kecil untuk bantalan yang diletakkan diantara contoh uji (agar larutan pengawet dapat meresap ke semua contoh uji) dan diberi pemberat di atasnya. Larutan pengawet dimasukan ke dalam bak sesuai dengan konsentrasi $(1 \%, 2 \%$ dan $4 \%)$ selama 1 jam.

4. Contoh uji diangkat dan dikeringkan/dilap dengan kain, kemudian contoh uji ditimbang berat setelah diawetkan untuk mengetahui nilai retensinya.

b. Perendaman panas dingin

1. Larutan pengawet tersebut dipanaskan dengan menggunakan kompor hingga $\pm 60^{\circ} \mathrm{C}$, pertahankan hingga siap dituang dalam bak lain.

2. Contoh uji dimasukan dan disusun ke dalam bak pengawet, diberi stik kecil untuk bantalan yang diletakkan diantara contoh uji (agar larutan pengawet dapat meresap ke semua contoh uji) dan diberi pemberat di atasnya. Larutan pengawet panas dimasukan ke dalam bak sesuai dengan konsentrasi $(1 \%, 2 \%$ dan $4 \%)$ selama 30 menit.
3. Kemudian matikan/angkat heater dan biarkan larutan pengawet tetap merendam contoh uji selama 30 menit.

4. Contoh uji diangkat dan dikeringkan/dilap dengan kain, kemudian contoh uji ditimbang berat setelah diawetkan untuk mengetahui nilai retensinya.

Nilai retensi dihitung dengan menggunakan rumus sebagai berikut:

Dimana:

$$
\mathrm{R}=\frac{\mathrm{B} 1-\mathrm{B} 2}{\mathrm{~V}} \times \frac{\mathrm{C}}{100}
$$

$\mathrm{R}=$ Retensi Bahan Pengawet $\left(\mathrm{kg} / \mathrm{m}^{3}\right)$

$\mathrm{B}_{1}=$ Berat Contoh Uji Setelah Diawetkan $(\mathrm{kg})$

$\mathrm{B}_{2}=$ Berat Contoh Uji Sebelum Diawetkan $(\mathrm{kg})$

$\mathrm{C}=$ Konsentrasi Bahan Pengawet (\%)

$\mathrm{V}=$ Volume Kayu yang Diawetkan $\left(\mathrm{m}^{3}\right)$

\section{Pengujian contoh uji}

Seluruh sampel baik yang sudah diawetkan maupun control (tidak diawetkan) akan dilakukan pengujian ketahanannya terhadap rayap tanah dengan menggunakan metode kuburan (Grave Yard Test). Metode kuburan ini mengacu pada modifikasi penelitian Priadi dan Parwiyati (2001) terdiri dari beberapa tahap sebagai berikut:

a. Contoh uji yang telah diawetkan dan kontrolnya dimasukan ke dalam oven dengan suhu $100^{\circ} \mathrm{C}$ selama 48 jam.

b. Kemudian contoh uji dimasukan ke dalam desikator selama \pm 15 menit sampai beratnya stabil.

c. Dilakukan penimbangan contoh uji sebelum dilakukan pengujian terhadap rayap tanah.

d. Selanjutnya contoh uji ditancapkan kira-kira sepanjang 3/4-nya ke sarang rayap tanah (temposo) secara acak.

e. Contoh uji diambil setelah 3 bulan penancapan. Sebelum dilakukan pengovenan, terlebih dahulu contoh uji dibersihkan dari kotoran-kotoran selama pengujian dengan menggunakan kuas.

f. Contoh uji dioven dengan suhu $100^{\circ} \mathrm{C}$ selama 48 jam. Kemudian contoh uji dimasukan ke dalam desikator selama \pm 15 menit sampai beratnya stabil.

g. Contoh uji ditimbang untuk mengetahui persentase kehilangan beratnya.

$$
\alpha=\frac{\mathrm{mb}-\mathrm{ms}}{\mathrm{mb}} \times 100 \%
$$

Dimana:

$$
\begin{array}{lll}
\alpha & = & \% \text { kehilangan berat } \\
\mathrm{m}_{\mathrm{s}} & = & \text { Massa contoh uji sesudah diujikan }(\mathrm{g}) \\
\mathrm{m}_{\mathrm{b}} & = & \text { Massa contoh uji sebelum diujikan }(\mathrm{g})
\end{array}
$$

D. Pengolahan Data

Pada penelitian menggunakan percobaan rancangan faktorian 3 x 2 dalam acak lengkap dengan 30 kali ulangan. Model umum matematika yang digunakan Haeruman (1972):

$\begin{array}{lll}\text { Dimana: } & & \text { Yijk }=\mu+\alpha \mathrm{i}+\beta \mathrm{j}+(\alpha \beta) \mathrm{ij}+ \\ \text { Yijk }= & \text { Nilai faktor pengamat } \\ \mu \quad= & \text { Rataan umum populasi }\end{array}$




$\begin{array}{ll}\alpha \mathrm{i}= & \text { Pengaruh faktor konsentrasi bahan } \\ \text { pengawet }(\mathrm{K}) & \\ \beta \mathrm{j}= & \text { Pengaruh faktor metode pengawetan } \\ (\mathrm{M}) & \\ (\alpha \beta) \mathrm{ij}= & \text { Pengaruh interaksi } \\ \text { cijk }= & \text { Kesalahan pengujian }\end{array}$

Data-data hasil penelitian yang diperoleh akan dianalisis keragamannya dengan menggunakan analisis sidik raga (ANOVA). Jika dalam perhitungan lebih lanjut dengan sidik ragam terdapat pengaruh yang berbeda $(\mathrm{F}$ hitung > F tabel), maka diadakan dengan uji lanjut dengan uji beda nyata terkecil (LSD) 5\% dan $1 \%$ untuk mengetahui perbedaan antara perlakuan dan menentukan perlakuanyang terbaik dengan menggunakan rumus (Haeruman, 1972).

\section{HASIL DAN PEMBAHASAN}

\section{A. Kadar Air dan Kerapatan}

Berdasarkan hasil penelitian pada kayu Trembesi (Albizia saman) diperoleh rataan kadar air kering udara, kerapatan kering udara dan kerapatan kering tanur seperti terlihat pada Tabel 2 berikut.

Tabel 2. Nilai Rataan Kadar Air dan Kerapatan pada Kayu Trembesi (Albizia saman)

\begin{tabular}{|c|c|c|}
\hline Sifat & Rataan & $\begin{array}{c}\text { Koefisien } \\
\text { Variasi }\end{array}$ \\
\hline Kadar air kering udara $(\%)$ & 11,528 & 4,445 \\
\hline $\begin{array}{c}\text { Kerapatan kering udara } \\
\left(\mathrm{g} / \mathrm{cm}^{3}\right)\end{array}$ & 0,460 & 8,500 \\
\hline $\begin{array}{c}\text { Kerapatan kering tanur } \\
\left(\mathrm{g} / \mathrm{cm}^{3}\right)\end{array}$ & 0,427 & 8,364 \\
\hline
\end{tabular}

Dari Tabel 2 di atas menunjukan bahwa nilai rataan kadar air kering udara Trembesi adalah 11,528 \% dengan koefisien variasi sebesar 4,445\%. Nilai rata-rata kerapatan kering udara dan kerapatan kering tanur masing-masing adalah $0,460 \mathrm{~g} / \mathrm{cm}^{3}$ dan $0,427 \mathrm{~g} / \mathrm{cm}^{3}$ dengan koefisien variasi masing-masing sebesar $8,500 \%$ dan $8,364 \%$.

\section{Kadar air}

Berdasarkan hasil pada Tabel 2 di atas dapat dijelaskan bahwa nilai rata-rata kadar air kering udara pada kayu Trembesi (Albizia saman) sebelum dilakukan pengawetan adalah $11,528 \%$, nilai kadar air ini masih di bawah kadar air titik jenuh serat $(<30 \%)$, sehingga sangat baik jika dilakukan proses pengawetan kayu dan akan membuat bahan pengawet lebih mudah masuk ke dalam kayu. Sejalan dengan itu Supraptono dan Bahrun (1981), menyatakan bahwa kadar air kayu untuk dapat diawetkan dengan baik harus berada di bawah titik jenuh serat atau 30\%. Lebih lanjut Supraptono, dkk (1981), mengatakan jika kadar air berada di atas titik jenuh serat akan sangat sulit dimpregnasi oleh pengawet karena di dalam rongga sel masih terdapat air, sementara itu kalau kadar air kayu tidak mencapai titik jenuh serat, air di dalam kayu sedikit maka bahan pengawet akan leluasa mengisi sel yang kosong tersebut.
Seperti yang dilaporkan Martawijaya (1974), kadar air memegang peranan penting dalam penembusan bahan pengawet ke dalam kayu.

Nilai kadar air kayu di bawah titik jenuh serat sangat dianjurkan untuk mencapai nilai retensi bahan pengawet yang baik, dimana menurut Yoesoef (1977), bahwa umumnya bahan pengawet akan terhalang masuk ke dalam rongga-rongga sel karena masih terisi oleh air, sebaliknya apabila kadar air di dalam rongga sel telah keluar atau hanya berjumlah sedikit maka bahan pengawet akan lebih mudah masuk ke dalam kayu.

\section{Kerapatan kayu}

Berdasarkan hasil pada tabel di atas dapat dijelaskan pengukuran nilai kerapatan menunjukan bahwa nilai rataan kerapatan kering udara dan kerapatan kering tanur kayu trembesi (Albizia saman) masing-masing sebesar $0,460 \mathrm{~g} / \mathrm{cm}^{3}$ dan $0,427 \mathrm{~g} / \mathrm{cm}^{3}$, ini membuktikan bahwa kerapatan kayu Trembesi termasuk ke dalam kelas kayu berkerapatan rendah. Hal ini sesuai dengan apa yang dikatakan oleh Dumanauw (2001), bahwa kayu yang memiliki berat jenis kurang dari $0,6 \mathrm{~g} / \mathrm{cm}^{3}$ termasuk ke dalam klasifikasi kayu dengan berat jenis rendah.

Kerapatan kayu sangat mempengaruhi penyerapan bahan pengawet. Kayu yang memiliki kerapatan rendah umumnya tersusun atas sel yang besar dibandingkan dengan kayu yang memiliki kerapatan tinggi, sehingga dapat menerima lebih banyak resapan bahan pengawet (Haygreen dan Bowyer, 1989). Bahan pengawet akan sangat mudah menembus kayu-kayu yang memiliki kerapatan rendah, sehingga kelompok kayu ini memiliki permeabilitas yang baik. Hal ini didukung oleh Hunt dan Garrat (1986), bahwa kayu yang berkerapatan rendah mempunyai pembuluh-pembuluh yang terbuka dan besar sehingga kayu jenis ini memiliki kemampuan menyerap bahan pengawet lebih baik jika dibandingkan dengan kayu yang berkerapatan tinggi.

\section{B. Nilai Retensi Bahan Pengawet}

Dari penelitian diperoleh nilai rataan retensi bahan pengawet Boraks dengan pelarut air dapat dilihat pada tabel berikut:

Tabel 3. Nilai Retensi Bahan Pengawet Boraks pada Kayu Trembesi (Albizia saman)

\begin{tabular}{|c|c|c|c|c|}
\hline \multirow{2}{*}{ Metode (M) } & \multicolumn{3}{|c|}{ Konsentrasi $\left(\mathbf{k g} / \mathbf{m}^{\mathbf{3}}\right)$} & \multirow{2}{*}{$\begin{array}{c}\text { Rataan } \\
\left(\mathbf{k g} / \mathbf{m}^{\mathbf{3}}\right)\end{array}$} \\
\cline { 2 - 4 } & $\mathbf{1 \%}$ & $\mathbf{2 \%}$ & $\mathbf{4 \%}$ & 0,718 \\
\hline $\begin{array}{c}\text { Perendaman } \\
\text { Dingin }\end{array}$ & 0,334 & 0,602 & 1,217 & $0,7,543$ \\
\hline $\begin{array}{c}\text { Perendaman } \\
\text { Panas Dingin }\end{array}$ & 0,665 & 1,302 & 2,662 & 1,543 \\
\hline Rataan & 0,499 & 0,952 & 1,939 & \\
\hline
\end{tabular}

Berdasarkan tabel di atas terlihat bahwa bahan pengawet Boraks dengan perbedaan konsentrasi dan metode pengawetan mempunyai nilai retensi yang berbeda. Semakin besar konsentrasi bahan pengawet dan semakin baik metode pengawetan yang digunakan maka semakin tinggi nilai retensi yang didapat. Rataan nilai retensi tertinggi terdapat pada konsentrasi $4 \%$ sebesar 
$2,662 \mathrm{~kg} / \mathrm{m}^{3}$ dengan menggunakan metode pengawetan panas dingin, sedangkan rataan nilai retensi terendah terdapat pada konsentrasi $1 \%$ sebesar $0,334 \mathrm{~kg} / \mathrm{m}^{3}$ dengan menggunakan metode perendaman dingin.

Kemudian untuk mengetahui pengaruh antara perlakuan maka dilakukan analisa sidik ragam terhadap nilai retensi yang hasilnya dapat dilihat pada tabel berikut:

Tabel 4. Analisa Sidik Ragam (ANOVA) Retensi Bahan Pengawet Boraks pada Kayu Trembesi (Albizia saman).

\begin{tabular}{|c|c|c|c|c|c|c|}
\hline $\begin{array}{c}\text { Sumber } \\
\text { Variasi }\end{array}$ & $\begin{array}{c}\text { Deraja } \\
\mathrm{t} \\
\text { Bebas } \\
(\mathrm{DB})\end{array}$ & $\begin{array}{c}\text { Jumlah } \\
\text { Kuadra } \\
\mathrm{t}(\mathrm{JK})\end{array}$ & $\begin{array}{c}\text { Kuadra } \\
\mathrm{t} \\
\text { Rataan } \\
(\mathrm{KR})\end{array}$ & F Hitung & 0,05 & 0,01 \\
\cline { 5 - 7 } Metode & 1 & 10,209 & 10,209 & $\begin{array}{c}179,623^{*} \\
*\end{array}$ & $\begin{array}{c}4,02 \\
0\end{array}$ & $\begin{array}{c}7,12 \\
9\end{array}$ \\
\hline $\begin{array}{c}\text { Konsentra } \\
\text { si }\end{array}$ & 2 & 21,685 & 10,843 & $\begin{array}{c}190,773^{*} \\
*\end{array}$ & $\begin{array}{c}3,16 \\
8\end{array}$ & $\begin{array}{c}5,02 \\
1\end{array}$ \\
\hline Interaksi & 2 & 3,224 & 1,612 & $28,363^{* *}$ & $\begin{array}{c}3,16 \\
8\end{array}$ & $\begin{array}{c}5,02 \\
1\end{array}$ \\
\hline Error & 54 & 3,069 & 0,057 & - & - & - \\
\hline Total & 59 & 38,187 & - & - & - & - \\
\hline
\end{tabular}

Keterangan: $* *=$ Berpengaruh Sangat Signifikan

Dari hasil dari analisa sidik ragam (ANOVA) pada Tabel 4 diketahui bahwa metode pengawetan (M), konsentrasi bahan pengawet $(\mathrm{K})$ dan interaksi antara metode pengawetan dengan konsentrasi bahan pengawet (MK) menunjukan adanya pengaruh yang sangat signifikan terhadap nilai retensi, untuk itu dilakukan uji lanjutan dengan menggunakan uji beda signifikan terkecil Least Significant Difference (LSD) yang hasilnya dapat dilihat pada tabel berikut:

Tabel 5. Uji Beda Signifikan Terkecil (LSD) Terhadap Metode Pengawetan yang Berbeda Terhadap Retensi.

\begin{tabular}{|c|c|c|c|c|c|}
\hline \multirow[b]{2}{*}{$\begin{array}{c}\text { Metode } \\
\text { Pengaweta } \\
n\end{array}$} & \multirow[b]{2}{*}{$\begin{array}{c}\text { Rataa } \\
\mathrm{n}\end{array}$} & \multicolumn{2}{|c|}{ Selisih Perlakuan } & \multicolumn{2}{|c|}{ LSD } \\
\hline & & $\begin{array}{l}\text { Perendam } \\
\text { an Dingin }\end{array}$ & $\begin{array}{c}\text { Perendam } \\
\text { an Panas } \\
\text { Dingin }\end{array}$ & 0,05 & 0,01 \\
\hline $\begin{array}{l}\text { Perendam } \\
\text { an Dingin }\end{array}$ & 0,718 & - & $0,825^{* *}$ & $\begin{array}{c}0,04 \\
2 \\
\end{array}$ & $\begin{array}{c}0,67 \\
2 \\
\end{array}$ \\
\hline $\begin{array}{c}\text { Perendam } \\
\text { an Panas } \\
\text { Dingin }\end{array}$ & 1,543 & - & - & - & - \\
\hline
\end{tabular}

Keterangan : $* *=$ Berbeda Sangat Signifikan

Hasil perhitungan uji beda signifikan terkecil (LSD) yang tercantum pada Tabel 5 menunjukan bahwa nilai rataan retensi bahan pengawet boraks pada kayu Trembesi (Albizia saman) berdasarkan metode perendaman panas dingin dan perendaman dingin telah menunjukan pengaruh metode yang berbeda serta menghasilkan nila retensi yang berbeda. Nilai retensi tertinggi $1,543 \mathrm{~kg} / \mathrm{m}^{3}$ dengan metode perendaman panas dingin dan nilai retensi terendah sebesar 0,718 $\mathrm{kg} / \mathrm{m}^{3}$ dengan metode perendaman dingin. Metode pengawetan dengan cara perendaman panas dingin menunjukan nilai retensi tertinggi, sedangkan nilai terendah didapat pada metode perendaman dingin. Jadi dapat dikatakan bahwa semakin baik metode pengawetan kayu yang direndam, semakin banyak udara yang keluar dari rongga-rongga sel maka akan menyebabkan nilai retensi bahan pengawet akan semakin tinggi.

Tabel 6. Uji Beda Signifikan Terkecil (LSD) Pengaruh Konsentrasi Bahan Pengawet Boraks Terhadap Retensi.

\begin{tabular}{|c|c|c|c|c|c|c|}
\hline \multirow{2}{*}{$\begin{array}{c}\text { Konsentras } \\
\mathrm{i}\end{array}$} & \multirow{2}{*}{$\begin{array}{c}\text { Rataa } \\
\mathrm{n}\end{array}$} & \multicolumn{3}{|c|}{ Selisih Perlakuan } & \multicolumn{2}{|c|}{ LSD } \\
\cline { 3 - 5 } & $\%$ & $2 \%$ & $4 \%$ & 0,05 & 0,01 \\
\hline $\mathrm{K} 1(1 \%)$ & 0,499 & - & $\begin{array}{c}0,453 * \\
*\end{array}$ & $\begin{array}{c}1,440^{*} \\
*\end{array}$ & & \\
\hline $\mathrm{K} 2(2 \%)$ & 0,952 & - & - & $\begin{array}{c}0,987 * \\
*\end{array}$ & $\begin{array}{c}0,05 \\
1\end{array}$ & $\begin{array}{c}0,67 \\
2\end{array}$ \\
\hline $\mathrm{K} 3(4 \%)$ & 1,939 & - & - & - & & \\
\hline
\end{tabular}

Keterangan : $* *=$ Berpengaruh sangat signifikan;

Hasil perhitungan yang tercantum pada tabel di atas menunjukan nilai retensi bahan pengawet Boraks pada masing-masing konsentrasi, yaitu nilai rataan retensi tertinggi pada konsentrasi $4 \%(\mathrm{~K} 3)$ sebesar $1,939 \mathrm{~kg} / \mathrm{m}^{3}$ dan yang terendah pada konsentrasi $1 \%$ (K1) sebesar $0,499 \mathrm{~kg} / \mathrm{m}^{3}$.

Berdasarkan hasil tersebut dapat dikatakan bahwa semakin tinggi konsentrasi bahan pengawet yang digunakan, maka nilai retensi yang dihasilkan semakin tinggi, hal ini dikarenakan dalam jumlah larutan yang sama umumnya terdapat kandungan senyawa kimia bahan pengawet akan lebih banyak terakumulasi pada konsentrasi yang lebih tinggi disbanding konsentrasi yang lebih rendah, hal ini dikarenakan banyaknya bahan pengawet yang akan terserap pada konsentrasi yang lebih tinggi. Pertimbangan ini sesuai dengan pendapat Yoesoef (1977) bahwa konsentrasi yang tinggi dari suatu bahan pengawet akan meningkatkan absorbsi kayu yang diawetkan, sehingga nilai retensinya akan lebih besar. Hal ini diperjelas oleh Hunt dan Garratt (1986), yang menyatakan bahwa untuk mencapai retensi yang diinginkan dari suatu bahan pengawet lebih baik diatur kepekaan larutannya daripada membatasi cairan yang dimasukan ke dalam kayu. Ditambahkan pula konsnetrasi bahan pengawet juga memegang peranan penting dalam pengawetan. Dimana semakin tinggi bahan pengawet maka akan mempermudah dan mempercepat masuknya bahan pengawet ke dalam kayu. Sejalan dengan itu Nicholas (1987), menyatakan bahwa bahan pengawet dengan konsentrasi yang tinggi dapat lebih meningkatkan laju retensi, sehinga pada waktu yang sama bahan pengawet dengan kensentrasi yang tinggi akan banayak masuk ke dalam kayu dibandingkan dengan bahan pengawet berkonsentrasi rendah. 
Tabel 7. Uji Beda Signifikan Terkecil (LSD) Pengaruh Interaksi Konsentrasi Bahan Pengawet (K) dan Metode Pengawetan (M) Terhadap Retensi.

\begin{tabular}{|c|c|c|c|c|c|c|c|c|c|}
\hline \multirow{2}{*}{$\begin{array}{l}\text { Inter } \\
\text { aksi }\end{array}$} & \multirow{2}{*}{$\begin{array}{l}\text { Rat } \\
\text { aan }\end{array}$} & \multicolumn{6}{|c|}{ Selisih Perlakuan } & \multicolumn{2}{|c|}{ LSD } \\
\hline & & $\begin{array}{l}\text { M1 } \\
\text { K1 }\end{array}$ & $\begin{array}{l}\text { M1 } \\
\text { K2 }\end{array}$ & $\begin{array}{l}\text { M1 } \\
\text { K3 }\end{array}$ & $\begin{array}{l}\text { M2 } \\
\text { K1 }\end{array}$ & $\begin{array}{l}\text { M2 } \\
\text { K2 }\end{array}$ & $\begin{array}{l}\text { M2 } \\
\text { K3 }\end{array}$ & & \\
\hline M1/ & 0,3 & & 0,26 & 0,88 & 0,33 & 0,96 & 2,32 & & \\
\hline $\mathrm{K} 1$ & 34 & & $8 * *$ & $3^{* *}$ & $0^{* * *}$ & $8 * *$ & $8^{* *}$ & & \\
\hline M1/ & 0,6 & & & 0,61 & 0,06 & 0,70 & 2,05 & & \\
\hline K2 & 02 & & & $4 * *$ & $2 *$ & $0^{* *}$ & $9^{* *}$ & & \\
\hline M1/ & 1,2 & & & & 0,55 & 0,08 & 1,44 & 0.0 & 1.1 \\
\hline $\mathrm{K} 3$ & 17 & & & & $2^{* * *}$ & $5^{*}$ & $5^{* *}$ & 88 & 64 \\
\hline M2/ & 0,6 & & & & & 0,63 & 1,99 & & \\
\hline K1 & 65 & & & & & $7 * *$ & $7 * *$ & & \\
\hline M2/ & 1,3 & & & & & & 1,36 & & \\
\hline K2 & 02 & & & & & & 0 ** & & \\
\hline M2/ & 2,6 & & & & & & & & \\
\hline K3 & 62 & & & & & & & & \\
\hline
\end{tabular}

Keterangan: $* *=$ Berbeda sangat signifikan, $*=$ Berbeda Signifikan

Menurut hasil uji lanjut LSD pada Tabel 7 diketahui bahwa interaksi antara metode pengawetan yaitu dengan cara perendaman dingin dan perendaman panas dingin dengan konsentrasi pengawet $1 \%, 2 \%$ dan $4 \%$ telah memberikan beda pengaruh yang sangat signifikan terhadap nilai retensi. Pada interaksi antar konsentrasi bahan pengawet dengan metode pengawetan terhadap nilai retensi yang tertinggi yaitu $2,662 \mathrm{~kg} / \mathrm{m}^{3}$ dengan metode pengawetan panas dingin dan konsentrasi $4 \%$, sedangkan nilai retensi terendah adalah $0,334 \mathrm{~kg} / \mathrm{m}^{3}$ dengan metode perendaman dingin menggunakan konsentrasi $1 \%$.

Secara umum semakin baik metode pengawetan yang digunakan semakin tinggi pula nilai retensi yang dihasilkan, dimana pada metode pengawetan panas dingin (M2) memiliki nilai retensi lebih tinggi dibanding dengan nilai retensi yang dihasilkan dari metode perendaman dingin (M1).

Dilihat dari hasil penelitaan yang ditulis oleh Ery (2012), nilai retensi pada perendaman panas dingin lebih tinggi dibanding dengan metode perendaman dingin dan juga metode pengawetan lainnya. Dari hasil ini dapat dikatakan bahwa metode perendaman panas dingin lebih efektif dibandingkan dengan metode pengawetan perendaman dingin dan metode pengawetan yang lainnya

Hal tersebut diperkuat oleh Dumanauw (2001), bahwa perendaman panas dingin lebih baik daripada rendaman dingin. Retensi dan penetrasi bahan pengawet lebih dalam dan banyak masuk ke dalam kayu.

Menurut Suranto (2002), perendaman kayu di dalam larutan pengawet panas dimaksudkan untuk mengeluarkan udara yang berada di lapisan kayu bagian luar dan menguapkan air yang ada di permukaan kayu tersebut. Dengan demikian, semakin tinggi suhu larutan pengawet pada kayu itu mulai di rendam, semakin banyak udara di keluarkan dan semakin banyak pula air yang diuapkan dari kayu.

\section{Kehilangan Berat}

Pengujian pada contoh uji kayu Trembesi baik yang mendapatkan perlakuan pengawetan kayu maupun kontrol dilakukan selama 3 bulan di sarang rayap tanah. Berikut ini merupakan nilai rataan persentase kehilangan berat pada contoh uji tanpa perlakuan (kontrol) dan dengan perlakuan menggunakan bahan pengawet boraks terhadap serangan rayap tanah dengan menggunkan metode penguburan.

Tabel 8. Nilai Rataan Persentase Kehilangan Berat pada

Kontrol dan Contoh Uji pada Kayu Trembesi (Albizia saman) dengan Bahan Pengawet Boraks.

\begin{tabular}{|c|c|c|c|c|}
\hline \multirow{2}{*}{ Metode } & \multicolumn{3}{|c|}{ Konsentrasi } & \multirow{2}{*}{ Rataan } \\
\cline { 2 - 4 } & K1 & K2 & K3 & \\
\hline Perendaman dingin & 3,678 & 3,533 & 3,250 & $\mathbf{3 , 4 8 7}$ \\
\hline $\begin{array}{c}\text { Perendaman Panas } \\
\text { Dingin }\end{array}$ & 1,636 & 1,479 & 1,339 & $\mathbf{1 , 4 8 4}$ \\
\hline Rataan & $\mathbf{2 , 6 5 7}$ & $\mathbf{2 , 5 0 6}$ & $\mathbf{2 , 2 9 4}$ & \\
\hline Kontrol & \multicolumn{4}{|c|}{9,573} \\
\hline
\end{tabular}

Keterangan : $\mathrm{K} 1=$ Konsentrasi $1 \%, \mathrm{~K} 2=$ Konsentrasi $2 \%, \mathrm{~K} 3=$ Konsentrasi $4 \%$

Bisa dilihat pada Tabel 8 di atas bahwa rataan penurunan kehilangan berat contoh uji semakin rendah dengan pertambahan konsentrasi bahan pengawet dan juga metode pengawetan yang digunakan. Untuk memperjelas gambaran rataan kehilangan berat pada contoh uji selama 3 bulan dapat dilihat pada grafik di halaman berikutnya:

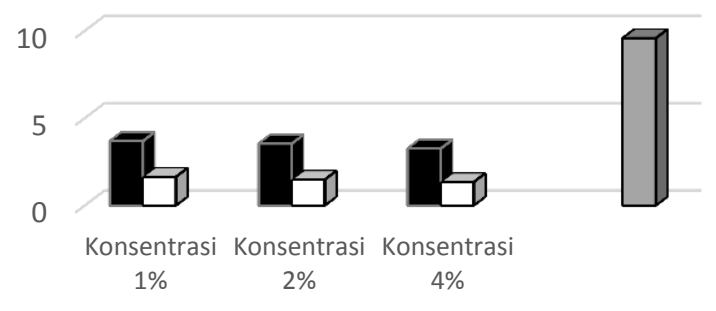

- Perendaman Dingin $\quad \square$ Perendaman Panas Dingin

$\square$ Kontrol

Gambar 1. Kehilangan Berat Contoh Uji Selama 3 Bulan Menggunakan Metode Perndaman Dingin dan

Perendaman Panas Dingin dengan Konsentrasi Berbeda pada Kayu Trembesi (Albizia saman).

Berdasarkan Gambar 1 di atas terlihat bahwa persentase kehilangan berat contoh uji akan semakin rendah seiring dengan pertambahan konsentrasi bahan pengawet, dapat dilihat pada gambar persentase kehilangna berat contoh uji dengan metode perendaman dingin yang menggunakan bahan pengawet Boraks. Adanya kencendrungan dimana pada retensi yang lebih tinggi maka serangan rayap akan berkurang sehingga persentase kehilangna berat akan menurun bahkan tidak terserang sama sekali. Berdasarkan hal tersebut dapat dikatakan bahwa penambahan konsentrasi bahan pengawet ternyata menghasilkan nilai serangan rayap yang semakin rendah pada contoh uji. 
Menurut Prasetyo dan Yusuf (2005) bahwa penggunaan kayu yang awet atau telah diawetkan dengan bahan pengawet anti rayap dapat mencegah serangan rayap. Sebagian besar jenis kayu kurang awet akan rentan terkena serangan rayap, kayu yang kurang awet sebenarnya bisa menjadi lebih awet dan tahan terhadap serangan rayap jika diberi perlakuan dengan bahan pengawet.

Lebih lanjut Hasan (1986), menjelaskan bahwa kayukayu bangunan yang dipasang kurang dari $15 \mathrm{~cm}$ di atas lantai atau tanah, dan kayu-kayu yang sudah diserang jamur merupakan tempat pertama yang terserang rayap tanah. Melalui lubang yang sangat kecil serangga ini masuk ke dalam kayu, semakin lama semakin dalam memanjang searah dengan serat kayu. Lapisan luar kayu tidak mereka ganggu, karena mereka perlukan untuk perlindungan terhadap lawan ataupun untuk memelihara kelembaban.

Selanjutnya untuk melihat masing-masing faktor (perlakuan) dar interaksi tersebut menunjukan pengaruh yang signifikan atau tidak terhadap nilai kehilangan berat maka dilakukan analisis sidik ragam (ANOVA) seperti terlihat pada Tabel 9 berikut ini:

Tabel 9. Analisis Sidik Ragam (ANOVA) Nilai Kehilangan Berat Kayu Trembesi (Albizia saman) Berdasarkan Metode Pengawetan dan Konsentrasi Bahan Pengawet yang Berbeda.

\begin{tabular}{|c|c|c|c|c|c|c|}
\hline \multirow{2}{*}{$\begin{array}{c}\text { Sumber } \\
\text { Variasi }\end{array}$} & \multirow{2}{*}{$\begin{array}{l}\text { Drajat } \\
\text { Bebas }\end{array}$} & \multirow{2}{*}{$\begin{array}{l}\text { Jumlah } \\
\text { Kuadrat }\end{array}$} & \multirow{2}{*}{$\begin{array}{c}\text { kuadrat } \\
\text { rataan }\end{array}$} & \multirow{2}{*}{$\begin{array}{c}\text { F. } \\
\text { Hitu } \\
\text { ng }\end{array}$} & \multicolumn{2}{|c|}{ F. Tabel } \\
\hline & & & & & $\begin{array}{l}\mathbf{0 , 0} \\
5 \%\end{array}$ & $\begin{array}{l}0,0 \\
1 \%\end{array}$ \\
\hline $\begin{array}{l}\text { Metode } \\
\text { (M) }\end{array}$ & 1 & 60,154 & 60,154 & $\begin{array}{c}85,09 \\
9 * *\end{array}$ & $\begin{array}{l}4,0 \\
20\end{array}$ & $\begin{array}{l}7,1 \\
29\end{array}$ \\
\hline $\begin{array}{c}\text { Konsentr } \\
\text { asi }(\mathrm{K})\end{array}$ & 2 & 1,327 & 0,663 & $\underset{\substack{\text { ns }\\
}}{0,938}$ & $\begin{array}{l}3,1 \\
68 \\
\end{array}$ & $\begin{array}{l}5,0 \\
21 \\
\end{array}$ \\
\hline $\begin{array}{c}\text { Interaksi } \\
(\mathrm{MK})\end{array}$ & 2 & 0,062 & 0,031 & $\underset{\substack{\text { ns } \\
0,044}}{ }$ & $\begin{array}{l}3,1 \\
68 \\
\end{array}$ & $\begin{array}{c}5,0 \\
21 \\
\end{array}$ \\
\hline Error & 54 & 38,171 & 0,707 & - & - & - \\
\hline Total & 59 & 99,714 & - & - & - & - \\
\hline
\end{tabular}

Setelah dilakukan analisis sidik ragam (ANOVA) terlihat bahwa konsentrasi dan interaksi menunjukan adanya pengaruh yang tidak signifikan terhadap nilai kehilangan berat, hal ini disebabkan oleh tidak adanya perbedaan yang terlalu jauh terhadap kehilangan berat yang disebabkan oleh masing-masing konsentrasi, sehingga jika dilakukan pengawetan menggunakan pengawet Boraks sangat disarankan untuk menggunakan konsentrasi $1 \%$ saja atau menggunakan konsentrasi lebih dari 4\%. Oleh sebab itu tidak perlu dilakukan uji lanjut (LSD) terhadap konsentrasi dan interaksi, sedangkan metode pengawetan menunjukan pengaruh yang sangat signifikan sehingga perlu dilakukan uji lanjut (LSD) sebagaimana pada tabel berikut.
Tabel 10. Uji Beda Signifikan Terkecil (LSD) Pengaruh Metode Pengawetan Terhadap Kehilangan Berat.

\begin{tabular}{|c|c|c|c|c|c|}
\hline $\begin{array}{c}\text { Metode } \\
\text { Perenda } \\
\text { man (M) }\end{array}$ & \multirow{2}{*}{$\begin{array}{c}\text { Rata } \\
\text { an } \\
(\%)\end{array}$} & $\begin{array}{c}\text { Selisih Perlakuan } \\
(\%)\end{array}$ & \multicolumn{2}{|c|}{ LSD } \\
\cline { 3 - 6 } & $\mathbf{M 1}$ & $\mathbf{M 2}$ & $\begin{array}{c}\mathbf{0 , 0 5} \\
\text { \% }\end{array}$ & $\begin{array}{c}\mathbf{0 , 0 1} \\
\text { \% }\end{array}$ \\
\hline Dingin & 3,487 & - & $2,003 * *$ & 0,14 & 0,99 \\
7 & - & 7 & 0 \\
\hline $\begin{array}{c}\text { Panas } \\
\text { Dingin }\end{array}$ & 1,484 & - & - & & \\
\hline
\end{tabular}

Keterangan : $* *=$ Berbeda sangat signifikan

Menurut hasil uji lanjut LSD yang tercantum pada Tabel 10 menunjukan bahwa nilai rataan kehilangan berat bahan pengawet Boraks pada kayu Trembesi terlihat bahwa metode pengawetan M2 (perendaman panas dingin) memberikan perbedaan paling signifikan dibandingkan metode pengawetan M1 (perendaman dingin). Karena pada perendaman panas dingin lebih banyak pengawet yang masuk ke dalam sel kayu sehingga memberikan pengaruh (efek racun) lebih baik terhadap serangan rayap dibanding dengan perendaman dingin.

Kemudian nilai kehilangan berat tersebut dibandingkan dengan SNI 01-7207-2006 tentang Klasifikasi Ketahanan Kayu Terhadap Rayap Tanah Berdasarkan Kehilangan Berat dapat dilihat pada tabel berikut:

Tabel 11. Klasifikasi Ketahanan Kayu Terhadap Rayap Tanah Berdasarkan Kehilangan Berat.

\begin{tabular}{|c|c|c|}
\hline Kelas & Ketahanan & Penurunan Berat (\%) \\
\hline I & Sangat tahan & $<3,52$ \\
\hline II & Tahan & $3,52-7,50$ \\
\hline II & Sedang & $7,50-10,96$ \\
\hline IV & Buruk & $10,96-18,94$ \\
\hline V & Sangat Buruk & $18,94-31,89$ \\
\hline
\end{tabular}

Sumber: SNI 01-7207-2006

Berdasarkan rataan persentase kehilangan berat contoh uji yang dihasilkan dalam penelitian diperoleh nilai dengan kisaran 1,339-3,678\% untuk contoh uji yang mendapatkan perlakuan pengawetan, sedangkan contoh uji kontrol sebesar 9,573\%. Nilai tersebut apabila dibandingkan dengan SNI 01-7207-2006 tentang uji ketahanan kayu dan produk kayu terhadap organisme perusak kayu termasuk dalam kelas I (sangat tahan) sampai dengan kelas II (tahan), sedangkan untuk kontrol termasuk dalam kelas III (sedang). Sehingga dapat dikatakan bahwa kehilangan berat contoh uji yang telah diberi perlakuan cukup efektif untuk pencegahan dari serangan rayap tanah.

\section{IV.KESIUMPULAN}

Berdasarkan dari hasil penelitian retensi bahan pengawet Boraks pada kayu Trembesi (Albizia saman) dan uji ketahanan terhadap serangan rayap tanah dapat disimpulkan:

1. Nilai rataan kadar air kering udara Trembesi adalah $11,528 \%$ dengan koefisien variasi sebesar $4,445 \%$. 
Nilai rata-rata kerapatan kering udara dan kerapatan kering tanur masing-masing adalah $0,460 \mathrm{~g} / \mathrm{cm}^{3}$ dan $0,427 \mathrm{~g} / \mathrm{cm}^{3}$ dengan koefisien variasi masing-masing sebesar $8,500 \%$ dan $8,364 \%$.

2. Nilai retensi tertinggi didapat pada konsentrasi $4 \%$ sebesar $1,939 \mathrm{~kg} / \mathrm{m}^{3}$ sedangkan nilai retensi terendah didapat pada konsentrasi $1 \%$ sebesar $0,499 \mathrm{~kg} / \mathrm{m}^{3}$.

3. Konsentrasi bahan pengawet Boraks dan metode pengawetan berpengaruh sangat signifikan terhadap retensi bahan pengawet, semakin tinggi konsentrasi pengawet maka semakin tinggi pula nilai retensi nya. Metode perendaman panas dingin dengan konsentrasi $4 \%$ menghasilkan nilai retensi lebih tinggi dibanding metode perendaman dingin dengan konsentrasi $1 \%$.

4. Interaksi antara faktor konsentrasi dan metode pengawetan berpengaruh sangat signifikan terhadap retensi, dimana rataan nilai retensi tertinggi dan paling memberikan pengaruh terhadap perlakuan interaksi yang lain terdapat pada konsentrasi $4 \%$ dengan metode pengawetan panas dingin sebesar 2,662 $\mathrm{kg} / \mathrm{m}^{3}$.

5. Kehilangan berat tertinggi didapat pada perendaman dingin sebesar 3,678\%, kelihangan berat terendah didapat pada perendaman panas dingin sebesar $1,339 \%$.

6. Konsentrasi dan interaksi menunjukan adanya pengaruh yang tidak signifikan terhadap nilai kehilangan berat, sedangkan metode pengawetan menunjukan pengaruh yang sangat signifikan dengan nilai kehilangan berat terendah yang paling berpengaruh adalah perendaman panas dingin sebesar $1,484 \%$. Namun perlakuan pengawetan secara umum telah mampu menurunkan kehilangan berat kayu.

Persentase kehilangan berat contoh uji yang dihasilkan dalam penelitian diperoleh nilai dengan kisaran 1,339$3,678 \%$ untuk contoh uji yang mendapatkan perlakuan pengawetan, sedangkan contoh uji kontrol sebesar 9,573\%. Nilai tersebut apabila dibandingkan dengan SNI 01-7207-2006 tentang uji ketahanan kayu dan produk kayu terhadap organisme perusak kayu termasuk dalam kelas I (sangat tahan) sampai dengan kelas II (tahan), sedangkan untuk kontrol termasuk dalam kelas III (sedang). Sehingga dapat dikatakan bahwa kehilangan berat contoh uji yang telah diberi perlakuan cukup efektif untuk pencegahan dari gan rayap tanah.

\section{DAFTAR PUSTAKA}

Abdurachman dan Jamaludin. M. 2013, Pemanfaatan Kayu Trembesi untuk Furnitur dengan Teknologi Laminasi, Botani Square IPB ICC, Bogor

Anonim, 2005. Pengawetan Kayu Ramah Lingkungan. Skripsi Sarjana Kehutanan. Samarinda. (Tidak Diterbitkan)

Anonim, 2007. Glue Laminated Timber. Japanese Agricultural Standard. MAFF, Final rev. Notofication No. 1152. Ministry Of Agriculture, Forestry and Fisheries. Japan.

Anderson. R.F. 1996. Forest and Shade Tree Entomologi. John Wiley and Sons. New York
Becker. G. 1976. Consecering Termite and Wood. Unosilv. Volume 28.No.III.FAO.Rome.

Borror. D. J. dan De Long. 1975. An Introduction to Study Insect Reinhartand Winston, New York

Dahlan, E.N. 2003. Karakteristik Anatomi dan Potensi Daun Trembesi (Albizia saman) di Ruas Jalan Kota Malang sebagai Akumulator Logam Berat Timbal $(\mathrm{Pb})$. Skripsi. Jurusan Biologi Fakultas Sains dan Teknologi. Universitas Islam Negeri Maulana Malik Ibrahim Malang.

Darmawan, O.T. 1980. Studi Tentang Penelitian Serangga Rayap pada Bangunan Rumah Kayu di Kotamadya Samarinda dan Sekitarnya. Skripsi Sarjana Fakultas Kehutanan Universitas Mulawarman. Samarinda (Tidak Diterbitkan)

Duljapar, K. 1996. Pengawetan Kayu. PT Penebar Swadaya. Jakarta.

Dumanauw.J.F. dan Virsarany. 1981. Mengenal Sifatsifat Kayu Indonesia dan Pengunaanya

Dumanauw, J.F. 2001. Mengenal Kayu. PT Gramedia. Jakarta.

Ery, P. 2012. Proses Pengawetan Tanpa Tekanan Menggunakan Pengawet Biotermikill 100 EC pada Kayu Gmelina (Gmelina arborea ROXB) dan Uji Ketahanannya Terhadap Serangan Rayap Tanah (Subtheranian termites). Skripsi Sarjana Kehutanan. Samarinda (Tidak diterbitkan)

Haeruman, H. 1972. Rancangan Percobaan Bagian Pertama. Bagian Perencanaan Departemen Managemen Hutan. Fakultas Kehutanan Bogor. IPB. Bogor.

Haygreen, J.G. dan J.L Bowyer. 1989. Hasil Hutan dan Ilmu Kayu. Gajah Mada University Press. Yogyakarta.

Hunt. G.M and G.A. Garratt. 1986. Pengawetan Kayu. CV Akademika Pressindo. Jakarta.

Martawijaya, A. 1974. Masalah Pengawetan Kayu di Indonesia. Kehutanan Indonesia Tahun I. Direktorat Jendral Kehutana, Jakarta.

Martawijaya, A. 1984. Pengawetan Lima Jenis Kayu Menurut Metode Perendaman Panas Dingin Oleh Baryl dan Pipin Permadi. Jurnal Penelitian Hasil Hutan.

Nandika, D. R.R. Raffiudin, E.A. Husaeni, 1991. Biologi Rayap Perusak Kayu. Pusat Antar Universitas Ilmu Hayat. IPB, Bogor.

Nandika. D.1995. Rayap dan Serangganya pada Bangunan Gedung. Makalah Penataran Superpisor Pengendalian Hama. Dinas Kesehatan-IPHAMI, Bogor.

Nandika, D. Y. Rismayadi dan F. Diba. 2003. Rayap, Biologi dan Pengendalian. Muhammadiyah University Press, Surakarta.

Nicholas, D.D. 1987. Kemunduran (Deteriorasi) Kayu dan pencegahannya dengan Perlakuan-perlakuan Pengawetan Jilid I dan II. Gajah Mada University Press. Yogyakarta.

Prasetyo. K.W. dan S. Yusuf. 2005. Mencegah dan Membasmi Rayap secara Ramah Lingkungan dan Kimiawi. PT. Agro Media Pustaka, Bogor. 
Priadi, T. dan Parwiyati. 2001. Keawetan dan Stabiltas Dimensi Kayu yang Diimpregnasi dengan Ekstrak Kulit Kayu Acacia mangium. Jurnal Teknologi Hasil Hutan. Fakultas Kehutanan. Institut Pertanian Bogor.

Supriana, N. 1975. Pengawetan Lima Jenis Kayu Menurut Metode Perendaman Panas Dingin Oleh Baryl dan Pipin Permadi. Jurnal Penelitian Hasil Hutan.

Supriana, N. 1983. Ekologi Rayap Perusak kayu. Risalah pada Diskusi Pencegahan dan Penangulanggan Bahaya Rayap pada Bangunan dan Ikatan Arsitek Indonesia, Jakarta.

Suranto, Y. 2002. Bahan dan Metode Pengawetan Kayu, Kanisius. Yogyakarta.

Suryowinoto. 1997. Flora Eksotika Tanaman Peneduh. Yogyakarta : Kanisius.

Tarumingkeng. R.C. 1971. Biologi dan Mengenal Rayap Perusak kayu di Indonesia. Laporan No: 38. LPHH Bogor.

Yoesoef, M. 1977. Pengawetan Kayu I. Yayasan Pembina Fakultas Kehutanan Universitas Gajah Mada.

Yogyakarta. 